\title{
Italian hospitals on the web: a cross-sectional analysis of official websites
}

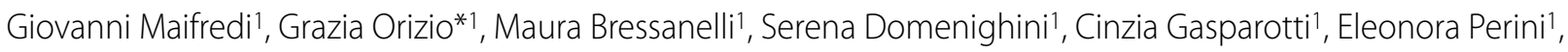 \\ Luigi Caimi2, Peter J Schulz ${ }^{3}$ and Umberto Gelatti ${ }^{1}$
}

\begin{abstract}
Background: Although the use of the Internet for health purposes has increased steadily in the last decade, only a few studies have explored the information provided by the websites of health institutions and no studies on the on-line activities of Italian hospitals have been performed to date. The aim of this study was to explore the characteristics of the contents and the user-orientation of Italian hospital websites.

Methods: The cross-sectional analysis considered all the Italian hospitals with a working website between December 2008 and February 2009. The websites were coded using an ad hoc Codebook, comprising eighty-nine items divided into five sections: technical characteristics, hospital information and facilities, medical services, interactive on-line services and external activities. We calculated a website evaluation score, on the basis of the items satisfied, to compare private ( $\mathrm{PrHs}$ ) and public hospitals, the latter divided into ones with their own website (PubHs-1) and ones with a section on the website of their Local Health Authority (PubHs-2). Lastly, a descriptive analysis of each item was carried out.

Results: Out of the 1265 hospitals in Italy, we found that 419 of the 652 public hospitals (64.3\%) and 344 of the 613 PrHs (56.1\%) had a working website $(p=0.01)$. The mean website evaluation score was 41.9 for PubHs-1, 21.2 for PubHs-2 and 30.8 for PrHs $(p<0.001)$.

Only 5 hospitals out of $763(<1 \%)$ provided specific clinical performance indicators, such as the nosocomial infection rate or the surgical mortality rates. Regarding interactive on-line services, although nearly $80 \%$ of both public and private hospitals enabled users to communicate on-line, less than $18 \%$ allowed the reservation of medical services, and only 8 websites (1\%) provided a health-care forum.
\end{abstract}

Conclusions: A high percentage of hospitals did not provide an official website and the majority of the websites found had several limitations. Very few hospitals provided information to increase the credibility of the hospital and user confidence in the institution. This study suggests that Italian hospital websites are more a source of information on admissions and services than a means of communication between user and hospital.

\section{Background}

Up-to-date statistics on Internet usage have revealed that Internet penetration rates among the population has reached $74.4 \%$ in North America and $48.8 \%$ in Europe, with impressive growth in recent years [1]. Besides, the use of the Internet for health purposes has steadily increased and it is now an important source of health information for patients and their families [2]. It has been

* Correspondence: gorizio@med.unibs.it

1 Section of Hygiene, Epidemiology and Public Health, Department of Experimental and Applied Medicine, University of Brescia, Brescia, Italy Full list of author information is available at the end of the article estimated that, worldwide, about $4.5 \%$ of searches on the web are health related [3]. A survey conducted in the US clearly shows that using the Internet as a health information resource remains the prevalent health-related activity of Internet users, much more frequent than the purchase of medicine or the participation in online support groups [4]. Studies in the US have found that $56 \%$ to $80 \%$ of Internet users have looked for health information online, including details of doctors and hospitals $[5,6]$, whereas the percentage of Internet health users in Europe ranges from $32 \%$ to $71 \%$, with vast differences between 
countries and in terms of user age, gender and standard of education [7].

Italian statistics show that $42 \%$ of women and $34 \%$ of men have looked for health information on the Internet [8], a percentage very similar to those observed in other south European countries, such as Greece and Portugal [7]. In Italy, too, women use the Internet for health purposes more frequently than men [8], as has already been observed in other studies, especially among young people $[4,7,9]$.

The potential public health impact of Internet use for health purposes has already been considered as both a public health threat and an advantage for users. Patients have direct access to information on diseases and treatments and they can even purchase online healthcare services, such as drugs, genetic tests and medical devices, thus bypassing the health professional, leading to possible risks [10-12]. Conversely, the potential of innovative communication tools for health care organizations in terms of public relations has already been reported and it represents an outstanding means of communication between users and institutions [13].

In addition, although the Internet is currently used more as a supplement to ordinary health services than a replacement of them, doctors should be aware that patients will increasingly ask for e-health services in the near future [14].

On their websites, health institutions such as hospitals can provide a large amount of information on the services they offer and how to access them, drawing the users' attention to themselves [15]. Patients can act as customers and decide to turn to the more attractive hospitals, hence a well-structured website can be the most effective way to gain patient confidence [16].

Recent advances in web technologies and user interfaces have greatly changed the web applications and in many cases transformed the way users interact with them [17]. The new generation of Internet devices and services can be very useful in facilitating participation and information sharing across a vast number of users [18], thus supporting personal involvement in hospital activities.

The aim of this study was to explore the information provided by the official websites of Italian hospitals and the possibility of interaction and communication between users and institutions via the Internet. To this end a cross-sectional study of all Italian hospital websites was conducted, and their technical characteristics and contents were analysed.

\section{Methods}

Study base

A list of all Italian hospitals was obtained from the Italian Ministry of Health (IMH) website updated to 1st January 2008 (see additional file 1). The hospitals were identified by an unambiguous code; records presenting the same identified code were considered only once, as they represent different administrative centres for the same hospital. We therefore included 1265 hospitals, meaning every Italian hospital, from the original 1570 records present in the IMH file.

\section{Website identification and selection}

The study was carried out in two stages. First, in November 2008, we searched for official hospital websites using the Google search engine, entering the hospital name and town as keywords. The first 30 references were analysed and websites not found using Google were actively searched for using a common services search engine (http://www.paginegialle.it/, Italian yellow pages), entering the name, town and address of the hospitals.

The Italian National Health Service (INHS) was established in 1978 on the British NHS model and subsequently underwent a major reform in the 1990s that introduced a quasi-market system, regionalization and managerialism [19]. Regionalism implies that jurisdiction over health-care issues is devolved at a regional level and for this reason we decided to present the results in Table 1 stratified by region. The quasi-market system introduced competition between public and accredited private providers [19]. Italian hospitals are therefore divided by the IMH into public and private ones. The majority of public hospitals are under the direct management of their Local Health Authority (LHA), and the websites of these hospitals are, in most cases, pages on the LHA website rather than a separate website. For this category of hospital we searched directly in the corresponding LHA website if the first two methods of website identification failed.

In order not to rule out this category of public hospital, these pages were included in the study, even if they did not have a proper website. However, we only included hospitals whose pages were clearly identified as single sections of the LHA websites and only information from these pages was taken into account.

Hospitals were classified into two groups according to their website: hospitals with an available and working website, defined as a working website (WW), and hospitals with a website that was not in operation or not available.

We therefore identified three categories of hospital with a WW: 1) Public hospitals with their own website, defined as public hospitals type 1 (PubHs-1); 2) Public hospitals with a section on the website of their LHA, defined as public hospitals type 2 (PubHs-2); 3 ) Private hospitals (PrHs), all of them with their own websites. We proceeded with an analysis of the websites of these three categories of hospitals by coding them. 
Table 1: Number and percentage of hospitals with a working website (WW)

\begin{tabular}{|c|c|c|c|c|c|c|c|}
\hline \multirow[t]{2}{*}{ Region } & \multicolumn{2}{|c|}{ Public hospitals } & \multicolumn{2}{|c|}{ Private hospitals } & \multirow[t]{2}{*}{ P value } & \multicolumn{2}{|c|}{ Total } \\
\hline & WWs/Tot & $\%$ WWs & WWs/Tot & $\%$ WWs & & WWs/Tot & $\% W W s$ \\
\hline Abruzzo & $9 / 22$ & 40.9 & $8 / 13$ & 61.5 & 0.24 & $17 / 35$ & 48.6 \\
\hline Basilicata & $5 / 10$ & 50.0 & $0 / 1$ & 0.0 & 0.34 & $5 / 11$ & 45.5 \\
\hline Calabria & $5 / 37$ & 13.5 & $13 / 39$ & 33.3 & 0.04 & $18 / 76$ & 23.7 \\
\hline Campania & $32 / 55$ & 58.2 & $33 / 71$ & 46.5 & 0.19 & $65 / 126$ & 51.6 \\
\hline Emilia-Romagna & $25 / 27$ & 92.6 & $33 / 48$ & 68.8 & 0.02 & $58 / 75$ & 77.3 \\
\hline Friuli Venezia Giulia & $13 / 16$ & 81.3 & $4 / 5$ & 80.0 & 0.95 & $17 / 21$ & 81.0 \\
\hline Lazio & $50 / 78$ & 64.1 & $56 / 99$ & 56.6 & 0.31 & 106/177 & 59.9 \\
\hline Liguria & $12 / 18$ & 66.7 & $5 / 10$ & 50.0 & 0.39 & $17 / 28$ & 60.7 \\
\hline Lombardy & $58 / 61$ & 95.1 & $64 / 82$ & 78.0 & 0.01 & $122 / 143$ & 85.3 \\
\hline Marches & $10 / 33$ & 30.3 & $7 / 13$ & 53.8 & 0.14 & $17 / 46$ & 37.0 \\
\hline Molise & $2 / 7$ & 28.6 & $1 / 3$ & 33.3 & 0.88 & $3 / 10$ & 30.0 \\
\hline Piedmont & $28 / 40$ & 70.0 & $25 / 51$ & 49.0 & 0.04 & $53 / 91$ & 58.2 \\
\hline Puglia & $20 / 38$ & 52.6 & $14 / 36$ & 38.9 & 0.24 & $34 / 74$ & 45.9 \\
\hline Sardinia & $29 / 32$ & 90.6 & $5 / 12$ & 41.7 & 0.01 & $34 / 44$ & 77.3 \\
\hline Sicily & $49 / 70$ & 70.0 & $32 / 65$ & 49.2 & 0.01 & $81 / 135$ & 60.0 \\
\hline Tuscany & $22 / 42$ & 52.4 & $18 / 31$ & 58.1 & 0.63 & $40 / 73$ & 54.8 \\
\hline $\begin{array}{l}\text { Trentino-Alto } \\
\text { Adige }\end{array}$ & $15 / 16$ & 93.8 & $8 / 11$ & 72.7 & 0.13 & $23 / 27$ & 85.2 \\
\hline Umbria & $8 / 11$ & 72.7 & $4 / 5$ & 80.0 & 0.76 & $12 / 16$ & 75.0 \\
\hline Aosta Valley & $0 / 1$ & 0.0 & $0 / 0$ & 0.0 & - & $0 / 1$ & 0.0 \\
\hline Veneto & $27 / 38$ & 71.1 & $14 / 18$ & 77.8 & 0.60 & $41 / 56$ & 73.2 \\
\hline Italy & $419 / 652$ & 64.3 & $344 / 613$ & 56.1 & 0.01 & $763 / 1265$ & 60.3 \\
\hline
\end{tabular}

\section{Coding of working websites}

The second stage of the study concerned WW coding. Between December 2008 and February 2009, five raters (MG, GC, PE, BM, DS) independently coded an equal number of websites, randomly assigned on the basis of the geographical region and category of the hospital, using an ad hoc Codebook (additional file 2) drawn up according to the Content Analysis Method [20].

The Codebook was first tested in a preliminary study that included a random sample of 40 hospitals. Subsequently, concordance among raters was analysed for 20 randomly chosen websites and a good agreement was observed (Cohen's Kappa statistic calculated for each website, among all raters, ranging from 0.69 to 0.88 , with a median value of 0.80 ).

In designing the Codebook, significant elements that emerged from previous studies $[15,21,22]$ and attributes concerning website user-orientation were both taken into account, as described in detail at the end of this sub-sec- tion. We focused more on the characteristics of the website contents than on informatics quality aspects.

The Codebook consisted of 89 items divided into five sections, focusing on different contents.

1) Technical contents: 19 items, including the presence of a site map and internal search engine, and the certification of accessibility to people with disabilities provided by the Web Accessibility Initiative (WAI) [23]. We recorded whether the websites provided W3C-css [24] and W3Chtml [25] certifications to assess whether the websites were in line with these technical informatics standards. We therefore looked for the presence of the Health On the Net (HON) foundation's logo as evidence of the reliability and credibility of the medical information provided by the site [26].

2) Hospital information and facilities: 22 items concerning general information, such as the history of the hospital, its location and ways of reaching the hospital, and contact details of the public relations office. 
3) Medical services: since a hospital website is a major source of information on admissions and services, we examined 25 items concerning hospital admission, discharge and everyday life during the hospitalization period and information about the doctors employed at the hospitals.

4) Interactive on-line services: we investigated hospital use of the Internet using 10 items, such as the availability of on-line reservations, being able to communicate with the hospital via the Internet or e-mail, and the presence of a health-related forum.

5) External activities: this section of the Codebook concerns 13 items, such as being able to obtain health information, job opportunities and a list of conferences organized by the hospital.

The structure of the Codebook was based on the study by Mira and coll [15], although some items were not taken into account and many were introduced as new ones. Some items concerning the transparency of the website were taken from the "Quality Principles for Cultural Websites: a handbook" by the Minerva Working Group 5 [22] and we introduced some quality items that emerged from a systematic review of empirical studies assessing the quality of health information on the Web [21]. We also introduced some new items in the "Admission and medical services" section, i.e. hospital quality indicators and items regarding the waiting list, because we were interested in studying the degree of user-orientation of the hospital websites and in the "Interactive online services" section, such as the possibility of signing up for a newsletter and the presence of a health-related forum, in order to study the degree of interaction between hospitals and users.

\section{Website evaluation score}

The Codebook was used to score each website, by identifying the presence or absence of the 89 items ( $1=$ item found, $0=$ item not found). We could therefore calculate a score for each website, defined as the website evaluation score, expressed as the percentage of items found over the total number of items, in order to compare the amount of information provided by each category of hospital, PubH-1, PubH-2 and PrH.

We first calculated a mean website evaluation score for each category of hospital, and subsequently we calculated a mean website evaluation score for each of the five sections of the Codebook to identify the strengths and weaknesses of each category of hospital.

In addition, a descriptive analysis item by item was conducted to assess the specific items for which the hospital websites failed and succeeded.

\section{Statistical analysis}

The findings were analysed using a descriptive and a quantitative approach.
Table 1 shows the percentage of WWs for public and private hospitals stratified by region. Table 2 sets out the mean website evaluation score for each of the five sections of the Codebook and considers the category of hospital as an independent variable and the sectional mean website evaluation score as a dependent variable.

Tables 3, 4, 5, 6 and 7 present each individual item (dependent variable) for the category of hospital (independent variable).

The Kruskal-Wallis one-way analysis of variance and the Wilcoxon rank-sum test were used to investigate differences in the distribution of the scores calculated between and within hospital categories. The chi-square test and the Fisher exact test, when appropriate, were used for categorical variables. In the analysis of the distribution of each item in the three categories of hospital, both the $\mathrm{p}$ value calculated for the comparison of the three categories of hospital and the $\mathrm{p}$ value calculated for PubHs-1 versus PrHs are disclosed.

We rejected the null hypothesis below a p value of 0.05 . All the analyses were conducted using the Stata statistical software package (version 10.0, Stata Corporation, College Station, Texas).

\section{Results}

\section{Working websites of public hospitals and PrHs}

The Italian National Health Service (INHS) comprises 1265 hospitals, as found in the IMH file, with vast differences in the total number and the proportion of public hospitals and PrHs between the 20 Italian regions. Table 1 shows a list of Italian regions with the corresponding number of hospitals, the percentage of WWs for public and private hospitals and the total number of hospitals.

We found that 419 of the 652 public hospitals $(64.3 \%)$ and 344 of the 613 PrHs (56.1\%) had a WW (p=0.01). Six regions out of 20 (Calabria, Emilia-Romagna, Lombardy, Piedmont, Sardinia and Sicily) showed a statistically significant difference between public and private hospitals in terms of the percentage of WWs and only in one case, the Calabria region, was the proportion higher among PrHs.

\section{Mean website evaluation score per section of the Codebook}

We calculated a mean website evaluation score for the five sections of the Codebook as shown in Table 2 (dependent variable), distributed by category of hospital (independent variable).

PubHs-1 scored better than the other categories in all sections except for "interactive on-line services". Indeed, in this section, PrHs scored 25.4, compared to 23.6 for PubHs-1, although the difference between these two categories was not statistically significant $(\mathrm{p}=0.36)$. PubHs2 provided the smallest amount of information in all the 
Table 2: Mean website evaluation score for each section of the Codebook, by category of hospital

\begin{tabular}{|c|c|c|c|c|c|}
\hline & \multirow[t]{2}{*}{$\begin{array}{l}\text { No. of items } \\
\text { per section }\end{array}$} & $\begin{array}{l}\text { Public hospitals } \\
\text { type } 1 \text { (PubHs-1)\# }\end{array}$ & $\begin{array}{l}\text { Public hospitals } \\
\text { type } 2 \text { (PubHs-2)\# }\end{array}$ & $\begin{array}{c}\text { Private hospitals } \\
\text { (PrHs) }\end{array}$ & \multirow[t]{2}{*}{$\begin{array}{c}p^{*} \\
\text { value }\end{array}$} \\
\hline & & \multicolumn{3}{|c|}{ mean percentage of items found } & \\
\hline 1. Technical items & 19 & $49.1(5.3-89.5)$ & $29.8(10.5-63.1)$ & $40.4(10.5-73.7)$ & $<0.001$ \\
\hline $\begin{array}{l}\text { 2. Hospital information } \\
\text { and facilities }\end{array}$ & 22 & $50.0(0-86.3)$ & $22.6(0-59.1)$ & $35.6(0-72.7)$ & $<0.001$ \\
\hline $\begin{array}{l}\text { 3. Admissions and } \\
\text { medical services }\end{array}$ & 25 & $40.6(0-76.0)$ & $26.0(0-60.0)$ & $32.3(0-76.0)$ & $<0.001$ \\
\hline $\begin{array}{l}\text { 4. Interactive on-line } \\
\text { services }\end{array}$ & 10 & $23.6(0-90.0)$ & $10.3(0-60.0)$ & $25.4(0-80.0)$ & $<0.001$ \\
\hline 5. External activities & 13 & $32.4(0-92.3)$ & $3.6(0-69.2)$ & $8.2(0-61.5)$ & $<0.001$ \\
\hline All & 89 & $41.9(7.9-72.7)$ & $21.2(4.5-42.0)$ & $30.8(5.7-61.3)$ & $<0.001$ \\
\hline
\end{tabular}

\# PubHs-1: Public hospitals with their own website; PubHs-2: Public hospitals with a section on the website of their LHA

${ }^{*}$ Kruskal-Wallis one-way analysis of variance.

sections and their mean score ranged from 29.8 for "website technical items" to 3.6 for "external activities".

\section{Descriptive analysis of the items included in the 5 sections of the Codebook}

A descriptive analysis, item by item for each section of the Codebook, is given in Tables 3, 4, 5, 6 and 7.

For each category of hospital, PubH-1, PubH-2 and PrH (independent variable), we assessed the percentage of hospital websites containing and not containing the single items (dependent variable) in the Codebook.

\section{Section 1: technical items}

Table 3 shows the percentage of hospital websites reporting the technical items.

The presence of different quality certification was assessed by identifying the corresponding logo on the home page (items 10-14). HON foundation certification (item 10) was present in only $4.5 \%$ of PubHs-1 and in no hospitals in the other two categories.

Certification of accessibility to people with disabilities (at least W3C WAI-A) (item 11) was present in less than $8 \%$ of the hospitals whereas certification of accessibility to people with disabilities by the Italian Authority on informatics in the public administration (item 14) was only present in two PubHs-2 (0.9\%) and in none of the hospitals in the other two categories.

Two items concerned the accountability of the websites: the date of the last website update (item 9) was poorly reported, in $20.2 \%$ (40/198), $6.3 \%(14 / 221)$ and $9.6 \%(33 / 344)$ of the three categories $(\mathrm{p}<0.001)$; no differences were found for the treatment of the surfers' per- sonal data (item 18), present for nearly $20 \%$ of the hospitals.

\section{Section 2: information and facilities}

Table 4 details the 22 items on hospital information and facilities in section 2 of the Codebook.

All the hospitals gave a high percentage of contact details (items 21-24), more than $80 \%$, but significantly more PrHs provided an address, telephone and/or fax number and e-mail address compared to PubHs-1 and PubHs-2.

Items 32-35 concerned the presence of a public relations office: more than $50 \%$ of PubHs-1 provided this information, whereas less than $17 \%$ of PrHs did so ( $\mathrm{p}<$ $0.001)$.

Three items, 36-38, concerned the transparency of the hospital towards its users: in particular, the results of patient satisfaction surveys were provided by less than $4 \%$ of the hospitals, with no significant differences among categories.

\section{Section 3: admissions and medical services}

Table 5 shows the 25 items included in section 3 of the Codebook, concerning admissions and medical services.

The first six items, $42-47$, concerned the availability of information regarding admissions, such as information and rules to be followed before, during and after the hospital stay. The different types of admission were disclosed in about $70 \%$ of PubHs- 1 and PrHs, and in nearly $50 \%$ of PubHs-2 (item 42). A complete list of departments or units providing user services (item 49) was present in at least $85 \%$ of the hospitals, and a list of detailed outpatient hospital services, including consultation and diagnostic services, was present in at least $70 \%$ of the hospitals, both 
Table 3: Percentage of hospitals presenting the specified item: technical items

\begin{tabular}{lccccc}
\hline Number and description of the & Public hospitals & Public hospitals & Private hospitals & $\mathbf{p}^{*}$ & $\mathbf{p}^{*}$ \\
item as it appears in the & type 1 (PubHs-1)\# & type 2 (PubHs-2)\# & (PrHs) & value & value \\
Codebook & $\mathbf{N}=198$ & $\mathrm{~N}=221$ & $\mathbf{N}=344$ & PubH-1 vs PrHs
\end{tabular}

$\%$ of hospitals reporting the item

1. Site name appears on browser title bar

2. Active part of the site appears on the browser title bar

3. Name of the hospital at the head of the website

4. Hospital logo at the head of the website

5. Any animation or visual displays can be bypassed

6. Access to the website in foreign languages

7. Website map available

8. Website searcher available

9. Date of last website update

10. Website has HON (Health On the Net) foundation code certification

11. Website has certification of accessibility to people with disabilities (at least W3C WAI-A logo)

12. Website has certification of Cascading Style Sheets validation (W3C CSS logo)

13. Website has certification of Markup Validation Service (W3C HTML logo)

14. Website has certification of accessibility to people with disabilities provided by the Italian authority on informatics in the public administration

15. Links with other useful websites provided (hospitals, scientific associations,

institutions)

16. General disclaimers provided

17. Copyright notice

18. Treatment of surfer personal data statement

19. Website pages can be printed

94.4

44.9

97.5

91.4

50.0

14.7

47.5

61.6

20.2

4.5

7.6

13.6

0

68.2

12.2

38.4

$<0.001$

$<0.001$

94.2

$<0.001$

0.91

34.9

0.01

0.02

0.65

0.78

0.89

0.26

$<0.001$

$<0.001$

$<0.001$

$<0.001$

$<0.001$

$<0.001$

$<0.001$

-

\# PubHs-1: Public hospitals with their own website; PubHs-2: Public hospitals with a section on the website of their LHA

\begin{tabular}{lcccc}
15.7 & 7.7 & 9.3 & 0.02 & 0.03 \\
36.9 & 28.5 & 37.2 & 0.08 & 0.93 \\
21.2 & 18.5 & 17.2 & 0.50 & 0.24 \\
83.8 & 90.5 & & & 0.37 \\
\hline
\end{tabular}

0.001
0.03
0.93
0.24
0.37

\footnotetext{
* Chi-square test or Fisher exact test, when appropriate
} 
Table 4: Percentage of hospitals presenting the specified item: hospital information and facilities

\begin{tabular}{|c|c|c|c|c|c|}
\hline \multirow[t]{2}{*}{$\begin{array}{l}\text { Number and description of the } \\
\text { item as it appears in the Codebook }\end{array}$} & $\begin{array}{c}\text { Public hospitals } \\
\text { type } 1 \text { (PubHs-1)\# } \\
N=198\end{array}$ & $\begin{array}{c}\text { Public hospitals } \\
\text { type } 2 \text { (PubHs-2)\# } \\
\text { N }=221\end{array}$ & $\begin{array}{c}\text { Private hospitals } \\
\text { (PrHs) } \\
\mathrm{N}=344\end{array}$ & \multirow[t]{2}{*}{$\begin{array}{c}\mathbf{p}^{*} \\
\text { value }\end{array}$} & \multirow[t]{2}{*}{$\begin{array}{c}\text { p* }^{*} \\
\text { value } \\
\text { PubH-1 Vs PrHs }\end{array}$} \\
\hline & \multicolumn{3}{|c|}{$\%$ of hospitals reporting the item } & & \\
\hline 20. Hospital history & 70.2 & 12.2 & 54.1 & $<0.001$ & $<0.001$ \\
\hline $\begin{array}{l}\text { 21. Contact details on the homepage } \\
\text { or available at a click: hospital postal } \\
\text { address }\end{array}$ & 86.4 & 81.0 & 92.2 & $<0.001$ & 0.03 \\
\hline $\begin{array}{l}\text { 22. Contact details on the homepage } \\
\text { or available at a click: telephone and/ } \\
\text { or fax number }\end{array}$ & 84.3 & 88.7 & 91.6 & 0.04 & 0.01 \\
\hline $\begin{array}{l}\text { 23. Contact details on the homepage } \\
\text { or available at a click: e-mail address }\end{array}$ & 67.2 & 30.8 & 79.4 & $<0.001$ & 0.01 \\
\hline $\begin{array}{l}\text { 24. Contact details on the homepage } \\
\text { or available at a click: VAT number }\end{array}$ & 40.9 & 12.7 & 42.7 & $<0.001$ & 0.68 \\
\hline 25. Statement of purpose & 64.1 & 7.2 & 53.5 & $<0.001$ & 0.02 \\
\hline $\begin{array}{l}\text { 26. ISO certification on the } \\
\text { homepage }\end{array}$ & 13.6 & 0.9 & 23.0 & $<0.001$ & 0.01 \\
\hline 27. Organisation chart & 68.7 & 19.9 & 30.8 & $<0.001$ & $<0.001$ \\
\hline $\begin{array}{l}\text { 28. Information regarding patient } \\
\text { privacy }\end{array}$ & 40.4 & 8.6 & 25.9 & $<0.001$ & $<0.001$ \\
\hline $\begin{array}{l}\text { 29. Ways of reaching the hospital: car, } \\
\text { public transport }\end{array}$ & 83.8 & 32.6 & 75.3 & $<0.001$ & 0.02 \\
\hline 30. Map of the hospital & 41.9 & 11.8 & 12.2 & $<0.001$ & $<0.001$ \\
\hline 31. Virtual visit to the hospital & 11.1 & 0.5 & 18.3 & $<0.001$ & 0.03 \\
\hline 32. Public relations office: work hours & 58.6 & 29.0 & 16.0 & $<0.001$ & $<0.001$ \\
\hline 33. Public relations office: location & 53.5 & 23.5 & 7.6 & $<0.001$ & $<0.001$ \\
\hline $\begin{array}{l}\text { 34. Public relations office: telephone } \\
\text { and/or fax number }\end{array}$ & 69.7 & 48.2 & 16.9 & $<0.001$ & $<0.001$ \\
\hline $\begin{array}{l}\text { 35. Public relations office: e-mail } \\
\text { address }\end{array}$ & 57.1 & 24.0 & 12.8 & $<0.001$ & $<0.001$ \\
\hline 36. Services charter & 58.1 & 7.7 & 34.0 & $<0.001$ & $<0.001$ \\
\hline 37. Patient's rights and obligations & 39.4 & 11.8 & 26.7 & $<0.001$ & 0.01 \\
\hline $\begin{array}{l}\text { 38. Results of surveys regarding } \\
\text { patient satisfaction are provided }\end{array}$ & 3.5 & 2.7 & 1.7 & 0.42 & 0.20 \\
\hline $\begin{array}{l}\text { 39. Information for General } \\
\text { Practitioners is provided }\end{array}$ & 3.0 & 0.5 & 0.6 & 0.02 & 0.02 \\
\hline $\begin{array}{l}\text { 40. Information for foreigners is } \\
\text { provided }\end{array}$ & 19.2 & 8.1 & 2.3 & $<0.001$ & $<0.001$ \\
\hline $\begin{array}{l}\text { 41. Complementary services: press, } \\
\text { cafeteria, television, telephone }\end{array}$ & 66.7 & 34.8 & 66.3 & $<0.001$ & 0.92 \\
\hline
\end{tabular}

\# PubHs-1: Public hospitals with their own website; PubHs-2: Public hospitals with a section on the website of their LHA

* Chi-square test or Fisher exact test, when appropriate

with no significant differences between private hospitals and PubHs-1.

Few hospitals disclosed the waiting list (item 54), 24.2\% (48/198) of PubHs-1, 9.5\% (21/221) of PubHs-2 and $13.4 \%(46 / 344)$ of PrHs ( $\mathrm{p}=0.01)$, and an even lower percentage gave the date on which the waiting list was last monitored, $17.7 \%$ (35/198), $4.1 \%(9 / 221)$ and $6.1 \%(21 /$ $344)$, respectively $(\mathrm{p}<0.001)$.

The doctors' curricula were disclosed in only $12.2 \%$ (24/ $198), 1.4 \%(3 / 221)$ and $8.7 \%(30 / 344)$ of the three categories of hospital, respectively $(\mathrm{p}<0.001)$. Information about hospital performance indicators was even rarer: 
only one hospital provided the nosocomial infection rate, two hospitals the inpatient mortality rate and three hospitals the surgical mortality rate, less than $1 \%$ of all the hospitals.

No difference was observed between PubHs-1 and PrHs with regard to information about private consultations or services (item 64), available in $69.2 \%$ (137/198) and $63.4 \%(218 / 344)$ of cases. Instead, some differences were found when we considered the cost of consultation or services available with fees: $10 \%$ of PubHs-1 (20/198) and only $1.5 \%$ of PrHs (5/344) provided this information (item 66, $\mathrm{p}<0.001$ ).

\section{Section 4: interactive on-line services}

This section comprised ten items, as shown in Table 6.

We established whether the Italian hospital websites allowed reservations via the Internet or e-mail: about 15\% of PubHs-1 and 18\% of PrHs accepted appointments for consultations or for services and admissions via the Internet (items 67 and 68). A higher percentage of hospitals offered the possibility to communicate (item 71), around $80 \%$ for both public hospitals and PrHs, or to obtain information about the hospital via the Internet or e-mail (item 73), 75.2\% of PubHs-1 (149/198) and 82.8\% of PrHs (285/344), $\mathrm{p}=0.03$. Very few hospitals, $6.1 \%$ of PubHs-1 (12/198), 8.1\% of PrHs (28/344) and none of the PubHs-2, enabled users to ask a specialist a health-related question via the Internet or e-mail (item 72), and only 8 websites out of $763(0.01 \%)$ - 5 PrHs (1.5\%) and 3 PubHs-1 (1.5\%) provided a health-related forum (item 76 ).

\section{Section 5: external activities}

The last section of the Codebook regards the external activities of the hospitals and comprises 13 items, as shown in Table 7.

In this section PubHs-1 presented the highest percentage for all the items, the difference between the three categories of hospital and between PubHs-1 and PrHs being statistically significant.

The possibility of reading online or downloading health-care booklets (item 77) was present in $19.2 \%$ of PubHs-1 (38/198), 7.2\% of PubHs-2 (16/221) and 10.8\% of PrHs (37/344). As regards information about associations that work at the hospital, details of voluntary associations were present in $46.0 \%(91 / 198), 11.8 \%(26 / 221)$ and $5.5 \%$ (19/344) (item 85), patient associations in $27.3 \%$ (54/ $198), 1.8 \%(4 / 221)$ and $1.4 \%(5 / 344)$ (item 86$)$ and associations for the defence of patients' rights in $17.2 \%$ (34/198), $7.2 \%(16 / 221)$ and $0.9 \%(3 / 344)$ (item 87$)$.

\section{Discussion}

This study examined the websites of all the Italian hospitals and documented that nearly the $40 \%$ of them do not have an official website. This percentage seems quite low considering that Norem, in a study of Norwegian hospital websites conducted in 2002 , found $80 \%$ of websites avail- able and this percentage is likely to have increased in recent years [16]. It looks as if many hospitals do not consider the web an important way of keeping in touch with their patients or enhancing visibility to potential users, although use of the Internet for health purposes has increased steadily in the last few years and this trend is likely to continue in the near future [5-8].

We found a significantly higher percentage of websites among public hospitals compared to private hospitals. Moreover, PubHs-1 scored better than PrHs, and PubHs2 provided the least information. This could partly be due to the fact that PubHs-1 are very often the main hospitals in the town, with the highest number of beds, and about $10 \%$ of them are university hospitals.

This trend was confirmed when we calculated the score for each of the five sections of the Codebook, with the exception of the section concerning interactive on-line services, where PrHs scored the same as PubHs-1.

Regarding the technical characteristics, less than $15 \%$ of the hospital websites were available in a foreign language, English in most cases. This percentage appears very low, considering tourism, immigration and patients coming from other countries for health reasons, as has already been pointed out [16].

Very few hospitals, less than $7 \%$, provided certification of website accessibility to people with disabilities. This finding is quite disappointing, especially because public institutions and private institutions providing services of public interest, such as health services, should have websites that are accessible to people with a disability.

Websites should provide the date of the last update for credibility reasons. In our study it was rarely reported, in less than $20 \%$ of PubHs- 1 and $10 \%$ of PrHs. A study that compared the websites of top Spanish, American and British hospitals [27] found $12 \%$ of them disclosed the date of the last update, a result very similar to that reported by Kind (10\%) [28], whereas Norwegian hospitals reached $40 \%$ [16].

As regards items concerning hospital information, contact details were provided by the great majority of hospitals but other items concerning a trust-based relationship between user and institution were much less likely to be reported. Only 19 out of $763(2.5 \%)$ hospitals with a WW reported the results of surveys regarding patient satisfaction, there being no differences between PubHs-1, PubHs-2 and PrHs. Moreover, waiting lists were disclosed in a quarter of PubHs- 1 and $13 \%$ of PrHs, and only 5 hospitals out of 763 , less than $1 \%$, provided specific clinical quality indicators, such as the nosocomial infection rate or inpatient and surgical mortality rates.

Information about consultations or services with fees was provided by more than $60 \%$ of PrHs and PubHs- 1 , but the costs of consultations and services with fees were only reported in $10 \%$ and $1.5 \%$, respectively. 
Table 5: Percentage of hospitals presenting the specified item: hospitalization and medical services

\begin{tabular}{|c|c|c|c|c|c|}
\hline \multirow[t]{2}{*}{$\begin{array}{l}\text { Number and description of the item } \\
\text { as it appears in the Codebook }\end{array}$} & $\begin{array}{c}\text { Public hospitals } \\
\text { type } 1 \text { (PubHs-1)\# } \\
\text { N = } 198\end{array}$ & $\begin{array}{l}\text { Public hospitals } \\
\text { type } 2 \text { (PubHs-2)\# } \\
\text { N = } 221\end{array}$ & $\begin{array}{c}\text { Private } \\
\text { hospitals(PrHs) } \\
\mathrm{N}=\mathbf{3 4 4}\end{array}$ & \multirow[t]{2}{*}{$\begin{array}{c}\mathbf{p}^{*} \\
\text { value }\end{array}$} & \multirow[t]{2}{*}{$\begin{array}{c}\text { p* } \\
\text { value } \\
\text { PubH-1 vs PrHs }\end{array}$} \\
\hline & \multicolumn{3}{|c|}{$\%$ of hospitals reporting the item } & & \\
\hline $\begin{array}{l}\text { 42. Admission guide: different types } \\
\text { of admissions are disclosed }\end{array}$ & 71.7 & 45.2 & 72.1 & $<0.001$ & 0.93 \\
\hline $\begin{array}{l}\text { 43. Admission guide: information and } \\
\text { rules to be followed on admission }\end{array}$ & 68.7 & 31.7 & 62.2 & $<0.001$ & 0.13 \\
\hline $\begin{array}{l}\text { 44. Admission guide: information and } \\
\text { rules to be followed during the } \\
\text { hospital stay }\end{array}$ & 55.1 & 19.5 & 43.9 & $<0.001$ & 0.01 \\
\hline $\begin{array}{l}\text { 45. Admission guide: information and } \\
\text { rules to be followed on discharge }\end{array}$ & 48.5 & 16.7 & 40.1 & $<0.001$ & 0.06 \\
\hline $\begin{array}{l}\text { 46. Admission guide: information and } \\
\text { rules to be followed regarding visits } \\
\text { by relatives }\end{array}$ & 66.7 & 43.0 & 59.6 & $<0.001$ & 0.10 \\
\hline $\begin{array}{l}\text { 47. Admission guide: information and } \\
\text { procedure for obtaining a copy of the } \\
\text { medical documentation }\end{array}$ & 65.2 & 47.1 & 43.0 & $<0.001$ & $<0.001$ \\
\hline $\begin{array}{l}\text { 48. Details of how to pay prescription } \\
\text { charges or fees }\end{array}$ & 44.4 & 33.0 & 17.4 & $<0.001$ & $<0.001$ \\
\hline $\begin{array}{l}\text { 49. Departments or units providing } \\
\text { user services: complete list }\end{array}$ & 89.9 & 93.7 & 84.9 & 0.01 & 0.10 \\
\hline $\begin{array}{l}\text { 50. Departments or units providing } \\
\text { user services: location }\end{array}$ & 63.1 & 43.9 & 24.1 & $<0.001$ & $<0.001$ \\
\hline $\begin{array}{l}\text { 51. Departments or units providing } \\
\text { user services: telephone and/or fax } \\
\text { number and/or e-mail address }\end{array}$ & 70.7 & 87.8 & 30.2 & $<0.001$ & $<0.001$ \\
\hline $\begin{array}{l}\text { 52. Detailed list of outpatient hospital } \\
\text { services available (consultation, } \\
\text { diagnostic services) }\end{array}$ & 78.3 & 71.0 & 79.9 & 0.04 & 0.65 \\
\hline 53. Number of hospital beds disclosed & 51.5 & 24.9 & 66.0 & $<0.001$ & 0.01 \\
\hline 54. Waiting list disclosed & 24.2 & 9.5 & 13.4 & $<0.001$ & 0.01 \\
\hline $\begin{array}{l}\text { 55. Date of last monitoring of the } \\
\text { waiting list disclosed }\end{array}$ & 17.7 & 4.1 & 6.1 & $<0.001$ & $<0.001$ \\
\hline $\begin{array}{l}\text { 56. Hospital report of the number of } \\
\text { admissions in the previous year }\end{array}$ & 10.6 & 3.2 & 6.7 & 0.01 & 0.11 \\
\hline 57. Doctors' curricula disclosed & 12.1 & 1.4 & 8.7 & $<0.001$ & 0.20 \\
\hline $\begin{array}{l}\text { 58. Hospital quality indicator: } \\
\text { nosocomial infection rate disclosed }\end{array}$ & 0 & 0 & 0.3 & 0.5 & 0.45 \\
\hline $\begin{array}{l}\text { 59. Hospital quality indicator: } \\
\text { inpatient mortality rate disclosed }\end{array}$ & 0.5 & 0 & 0.6 & 0.5 & 0.91 \\
\hline $\begin{array}{l}\text { 60. Hospital quality indicator: surgical } \\
\text { mortality rate disclosed }\end{array}$ & 0 & 0 & 0.6 & 0.3 & 0.28 \\
\hline 61. Hospital quality indicator: others & 11.6 & 1.4 & 13.4 & $<0.001$ & 0.55 \\
\hline $\begin{array}{l}\text { 62. List of employed doctors in } \\
\text { alphabetical order }\end{array}$ & 9.6 & 0 & 4.1 & $<0.001$ & 0.01 \\
\hline $\begin{array}{l}\text { 63. List of employed doctors by } \\
\text { specialisation }\end{array}$ & 47.5 & 31.7 & 45.6 & $<0.001$ & 0.68 \\
\hline $\begin{array}{l}\text { 64. Information about private } \\
\text { consultations/services and fees }\end{array}$ & 69.2 & 28.5 & 63.4 & $<0.001$ & 0.17 \\
\hline $\begin{array}{l}\text { 65. List of consultations/services with } \\
\text { fees available }\end{array}$ & 27.8 & 9.5 & 19.5 & $<0.001$ & 0.03 \\
\hline $\begin{array}{l}\text { 66. Cost of consultations/services with } \\
\text { fees available }\end{array}$ & 10.1 & 4.5 & 1.5 & $<0.001$ & $<0.001$ \\
\hline
\end{tabular}

\# PubHs-1: Public hospitals with their own website; PubHs-2: Public hospitals with a section on the website of their LHA

${ }^{*}$ Chi-square test or Fisher exact test, when appropriate 
Table 6: Percentage of hospitals presenting the specified item: interactive on-line services

\begin{tabular}{|c|c|c|c|c|c|}
\hline \multirow[t]{2}{*}{$\begin{array}{l}\text { Number and description } \\
\text { of the item as it appears } \\
\text { in the Codebook }\end{array}$} & $\begin{array}{c}\text { Public hospitals } \\
\text { type } 1 \text { (PubHs-1)\# } \\
\text { N }=198\end{array}$ & $\begin{array}{c}\text { Public hospitals } \\
\text { type } 2 \text { (PubHs-2)\# } \\
\text { N }=221\end{array}$ & $\begin{array}{c}\text { Private } \\
\text { hospitals(PrHs) } \\
\mathbf{N}=\mathbf{3 4 4}\end{array}$ & \multirow[t]{2}{*}{$\begin{array}{c}\mathbf{p}^{*} \\
\text { value }\end{array}$} & \multirow[t]{2}{*}{$\begin{array}{c}\mathbf{p}^{*} \\
\text { value } \\
\text { PubH-1 vs PrHs }\end{array}$} \\
\hline & \multicolumn{3}{|c|}{$\%$ of hospitals reporting the item } & & \\
\hline $\begin{array}{l}\text { 67. Appointments for } \\
\text { consultation via the } \\
\text { Internet }\end{array}$ & 15.1 & 1.4 & 18.6 & $<0.001$ & 0.31 \\
\hline $\begin{array}{l}\text { 68. Appointments for } \\
\text { services/admission via the } \\
\text { Internet }\end{array}$ & 14.7 & 1.4 & 18.0 & $<0.001$ & 0.31 \\
\hline $\begin{array}{l}\text { 69. Other facilities } \\
\text { available via the Internet } \\
\text { (e.g. documentation) }\end{array}$ & 2.0 & 0.5 & 4.4 & 0.015 & 0.15 \\
\hline $\begin{array}{l}\text { 70. Appointments for } \\
\text { consultation/services/ } \\
\text { admission via the } \\
\text { Internet: link on the } \\
\text { homepage }\end{array}$ & 11.6 & 1.4 & 16.6 & $<0.001$ & 0.12 \\
\hline $\begin{array}{l}\text { 71. Possibility to } \\
\text { communicate with the } \\
\text { hospital via the Internet or } \\
\text { e-mail }\end{array}$ & 79.8 & 48.4 & 85.2 & $<0.001$ & 0.11 \\
\hline $\begin{array}{l}\text { 72. Possibility to ask a } \\
\text { specialist a health-related } \\
\text { question via the Internet } \\
\text { or e-mail }\end{array}$ & 6.1 & 0 & 8.1 & $<0.001$ & 0.37 \\
\hline $\begin{array}{l}\text { 73. Information request } \\
\text { form via the Internet or } \\
\text { e-mail }\end{array}$ & 75.2 & 47.1 & 82.8 & $<0.001$ & 0.03 \\
\hline $\begin{array}{l}\text { 74. Suggestions/ } \\
\text { complaints form via the } \\
\text { Internet or e-mail }\end{array}$ & 17.2 & 2.7 & 10.2 & $<0.001$ & 0.02 \\
\hline $\begin{array}{l}\text { 75. Possibility to sign up } \\
\text { for a newsletter }\end{array}$ & 13.1 & 0.5 & 8.4 & $<0.001$ & 0.08 \\
\hline $\begin{array}{l}\text { 76. A health-related forum } \\
\text { is present }\end{array}$ & 1.5 & 0 & 1.5 & 0.20 & 0.95 \\
\hline
\end{tabular}

\# PubHs-1: Public hospitals with their own website; PubHs-2: Public hospitals with a section on the website of their LHA

* Chi-square test or Fisher exact test when appropriate

With regard to interactive on-line services, the results suggest that the Internet is used by hospitals as a means of communication, but real interaction between users and the institution appears far from being achieved. Indeed, the possibility of communicating via the Internet or e-mail was available in about $80 \%$ of PrHs and PubHs1 , but a form for asking a specialist health-related questions was available in less than $10 \%$ of the hospitals. A health-related forum was present for only 3 out of 198 PubHs-1 and 5 out of 344 PrHs, less then 1.5\%. The use of new-generation Internet devices appears to be very lim- ited on Italian hospital websites, which are more a source of information, from institution to users, than a way of participating and interacting with the institution's activities.

With regard to the results of the external activities of the websites, it is not surprising that PubHs-1 scored better than the rest. Compared to the other categories of hospital, PubHs-1 are closer to the academic and scientific environment, undergraduate or postgraduate courses being held in nearly half of them. They seem to be more integrated with the area they serve since volun- 
Table 7: Percentage of hospitals presenting the specified item: external activities

\begin{tabular}{|c|c|c|c|c|c|}
\hline \multirow[t]{2}{*}{$\begin{array}{l}\text { Number and description } \\
\text { of the item as it appears } \\
\text { in the Codebook }\end{array}$} & $\begin{array}{c}\text { Public hospitals } \\
\text { type } 1 \text { (PubHs-1)\# } \\
\text { N }=198\end{array}$ & $\begin{array}{c}\text { Public hospitals } \\
\text { type } 2 \text { (PubHs-2)\# } \\
\text { N = } 221\end{array}$ & $\begin{array}{c}\text { Private hospitals } \\
\text { (PrHs) } \\
\mathrm{N}=\mathbf{3 4 4}\end{array}$ & \multirow[t]{2}{*}{$\begin{array}{c}\mathbf{p}^{*} \\
\text { value }\end{array}$} & \multirow[t]{2}{*}{$\begin{array}{c}\mathbf{p}^{*} \\
\text { value } \\
\text { PubH-1 vs PrHs }\end{array}$} \\
\hline & \multicolumn{3}{|c|}{$\%$ of hospitals reporting the item } & & \\
\hline $\begin{array}{l}\text { 77. Possibility to read } \\
\text { online or to download } \\
\text { health-care booklets }\end{array}$ & 19.2 & 7.2 & 10.8 & 0.01 & 0.01 \\
\hline $\begin{array}{l}\text { 78. Medical glossary } \\
\text { available }\end{array}$ & 4.6 & 0.5 & 0.6 & $<0.001$ & 0.01 \\
\hline $\begin{array}{l}\text { 79. Scientific studies that } \\
\text { the hospital promotes or } \\
\text { is involved in }\end{array}$ & 36.9 & 3.7 & 8.7 & $<0.001$ & $<0.001$ \\
\hline $\begin{array}{l}80 \text {. Undergraduate or } \\
\text { postgraduate courses that } \\
\text { are held at the hospital }\end{array}$ & 44.9 & 1.8 & 13.1 & $<0.001$ & $<0.001$ \\
\hline 81. Presence of a library & 28.8 & 1.4 & 1.7 & $<0.001$ & $<0.001$ \\
\hline $\begin{array}{l}\text { 82. Schedule of activities } \\
\text { that take place at the } \\
\text { hospital: courses, } \\
\text { congresses and } \\
\text { conferences }\end{array}$ & 65.1 & 3.2 & 26.5 & $<0.001$ & $<0.001$ \\
\hline $\begin{array}{l}\text { 83. Publication of the } \\
\text { hospital itself }\end{array}$ & 26.8 & 0.5 & 8.1 & $<0.001$ & $<0.001$ \\
\hline $\begin{array}{l}\text { 84. Details of job } \\
\text { opportunities at the } \\
\text { hospital }\end{array}$ & 63.1 & 6.3 & 17.4 & $<0.001$ & $<0.001$ \\
\hline $\begin{array}{l}\text { 85. Associations that work } \\
\text { at the hospital: voluntary } \\
\text { associations }\end{array}$ & 46.0 & 11.8 & 5.5 & $<0.001$ & $<0.001$ \\
\hline $\begin{array}{l}\text { 86. Associations that work } \\
\text { at the hospital: patient } \\
\text { associations }\end{array}$ & 27.3 & 1.8 & 1.4 & $<0.001$ & $<0.001$ \\
\hline $\begin{array}{l}\text { 87. Associations that work } \\
\text { at the hospital: } \\
\text { associations for the } \\
\text { defence of patients' rights }\end{array}$ & 17.2 & 7.2 & 0.9 & $<0.001$ & $<0.001$ \\
\hline $\begin{array}{l}\text { 88. Information on how to } \\
\text { make a donation to the } \\
\text { hospital }\end{array}$ & 20.2 & 0 & 4.1 & $<0.001$ & $<0.001$ \\
\hline $\begin{array}{l}\text { 89. The hospital in the } \\
\text { media: press review }\end{array}$ & 20.7 & 0.9 & 7.8 & $<0.001$ & $<0.001$ \\
\hline
\end{tabular}

\# PubHs-1: Public hospitals with their own website; PubHs-2: Public hospitals with a section on the website of their LHA

* Chi-square test or Fisher exact test, when appropriate

tary and patient associations are present on many of their websites.

As regards the limitations of the study, many websites may have changed during the three-month survey as they are updated very quickly, or some hospitals without website may have gone on line.
We stratified the data on the basis of region and category of hospital (public versus private) mainly because the INHS is based on regionalization and competition between public and accredited private providers. It was not possible to stratify the results based on the number of hospital beds since this information was not available from an institutional source and few hospitals declared it 
on their websites. Other variables, however, such as specialized or general hospitals and university hospitals, are relevant for cross-sectional analysis and could be considered in future research.

Several considerations can be made regarding to the validity of the study, in terms of Codebook and intercoder reliability. As anticipated in the method section, the Codebook drawn up for this study attempted to integrate the items previously proposed by researchers studying hospital websites with new issues, especially the investigation of website user-orientation. We tested the Codebook in a preliminary study of 40 hospitals websites in order to assess its completeness in evaluating the characteristics of the website contents rather than informatics quality aspects. Again with regard to the study limitations, there are many ways to study a website and different criteria have already been proposed [15,16,21,22,27]. It is therefore possible that a different evaluation scale could have changed the results. However, the differences among the three hospital categories are consistent within all the sections of the Codebook, which suggests its internal coherence and face validity.

Five raters coded an equal number of websites to deal with the large number of hospitals found. The concordance study revealed a very good agreement among raters, hence a meeting to settle disagreements between raters preceded the final coding of the websites, although a certain variability in the coding cannot be ruled out.

As a methodological consideration, we used a descriptive approach since as far as we know there is no benchmark research in Italy in this field. This study can be therefore be considered a baseline survey at this time in the history of consumer health informatics literature in Italy.

Moreover, the proposed Codebook may provide a useful prototype for baseline surveys in countries where similar hospital-Internet diffusion evaluations have not occurred. It is difficult to generalize the study's findings to other countries because Italy has a unique health care organizational infrastructure and Internet usage patterns differ internationally. However, the Internet's dynamic nature suggests it is important to assess its use and potential by hospitals and medical care organizations in diverse nations. In this regard, the Codebook of this study may be adaptable for use in other countries regardless of their level of Internet and e-health acceptance, including ones where hospitals use Web 2.0 tools and ones where public access to the Internet and health information technology is emerging.

\section{Conclusions}

This is the first study to examine the websites of all Italian hospitals. A high percentage of hospitals did not provide an official website; compared to private hospitals, public hospitals were more likely to have a website and more information. We found a greatly varying scenario, with a few excellent websites and others with poor quality and very scant information. These results suggest that the majority of Italian hospital websites have several limitations.

Very few hospitals provided information likely to increase the credibility of the hospital and user confidence in the institutions, as the results of surveys regarding patient satisfaction and clinical quality indicators point out.

These indicators, such as standardised hospital mortality rate, are increasingly being used to compare hospital performance and to satisfy public demand for transparency. The UK National Health Service [29] and the French Ministry of Health give examples that provide these data in clear and easy-to-use databases [30].

It would appear that Italian hospitals, even leading ones, are not interested in promoting their performance, even if they detail the medical services they offer. This could be due to the fact that patients are still using other methods for choosing hospitals; advice from friends and relatives, word of mouth and the general practitioner still seem to play a major role in choosing the best place to be treated. This study also indicates that Italian hospital websites remain more a source of information on admissions and services than an interactive platform for communication between users and hospitals, since interactive tools, such as a health-related forum and the possibility to sign up for a newsletter, are virtually absent.

Public health institutions should not ignore these emerging means of communication, especially in terms of health promotion. As there is a huge amount of health information available outside institutional channels, hospitals, like other health institutions, should provide reliable information via their websites and promote contents that can get ahead of potentially harmful advertising [31].

\section{Additional material}

\begin{abstract}
Additional file 1 List of all Italian hospitals updated to 1st January
2008. The list of all Italian hospitals has been obtained from the Italian Ministry of Health website (modified as regards the column headings). The original file is available at: http://www.ministerosalute.it/servizio/documenti/INDIRIZZO STRUTTURE 1 gennaio 2008.xIs. Last accessed 2 July 2009.

Additional file $\mathbf{2}$ Codebook. List of the eighty-nine items included in the study.
\end{abstract}

\section{Abbreviations}

LHA: Local Health Authority; INHS: Italian National Health Service; PubHs-1: Public hospitals with their own website; PubHs-2: Public hospitals with a section on the website of their Local Health Authority; PrHs: Private hospitals.

\section{Competing interests}

The authors declare that they have no competing interests. 


\section{Authors' contributions}

GM developed the study design, conducted the statistical analysis and drafted the manuscript. GO assisted with data interpretation and drafted the manuscript. MB, SD, CG, EP were involved in data acquisition and assisted with data interpretation. LC and PJS reviewed the manuscript critically and gave final approval of the version to be published. UG developed the study design, supervised the study and reviewed the manuscript critically. All the authors read and approved the final manuscript.

\section{Acknowledgements}

The study was performed at the Section of Hygiene Epidemiology and Public Health, University of Brescia, Italy, in collaboration with the "Quality and Technology Assessment, Governance and Communication Strategies in Health Systems" Study and Research Centre, University of Brescia, Italy, without additional financial support.

\section{Author Details}

1Section of Hygiene, Epidemiology and Public Health, Department of Experimental and Applied Medicine, University of Brescia, Brescia, Italy, 2"Quality and Technology Assessment, Governance and Communication Strategies in Health Systems" Study and Research Centre, University of Brescia, Brescia, Italy and 3Institute of Communication and Care, University of Lugano, Lugano, Switzerland

Received: 11 September 2009 Accepted: 1 April 2010

Published: 1 April 2010

\section{References}

1. Internet World Stats: Usage and Population Statistics. Internet usage statistics. The Internet Big Picture. World Internet Users and Population Stats. [http://www.internetworldstats.com/stats.htm].

2. Mukhopadhyay RS, Waller A, Franklin VL: What do UK children's hospital websites offer patients and families? Arch Dis Child 2008, 93:179-80.

3. Eysenbach $\mathrm{G}$, Kohler Ch: What is the prevalence of health-related searches on the World Wide Web? Qualitative and quantitative analysis of search engine queries on the internet. AMIA Annu Symp Proc 2003:225-9.

4. Atkinson NL, Saperstein SL, Pleis J: Using the Internet for Health-Related Activities: Findings From a National Probability Sample. J Med Internet Res 2009, 11(1):e4.

5. Ybarra ML, Suman M: Help seeking behavior and the Internet: a national survey. Int J Med Inform 2006, 75:29-41.

6. Fox S, Jones S: The Social Life of Health Information. Americans' pursuit of health takes place within a widening network of both online and offline sources. 2009 [http://pewinternet.org/Reports/2009/8-TheSocial-Life-of-Health-Information/01-Summary-of-Findings.aspx? $r=1$ ]

7. Kummervold PE, Chronaki CE, Lausen B, Prokosch H, Rasmussen J, Santana S, Staniszewski A, Wangberg SC: eHealth Trends in Europe 20052007: A Population-Based Survey. J Med Internet Res 2008, 10(4):e42.

8. Istituto nazionale di statistica (Istat): Le tecnologie dell'informazione e della comunicazione: disponibilità nelle famiglie e utilizzo degli individui. Statistiche in Breve. 2008 [http://www.istat.it/salastampa/ comunicati/non calendario/20080116 00/testointegrale20080116.pdf]. In Italian. National Institute of Statistics (Istat). Information and communication technologies: availability among families and individual use

9. Wangberg SC, Andreassen HK, Prokosch HU, Santana SM, Sørensen T, Chronaki CE: Relations between Internet use, socio-economic status (SES), social support and subjective health. Health Promot Int 2008, 23:70-7.

10. Orizio G, Schulz P, Domenighini S, Caimi L, Rosati C, Rubinelli S, Gelatti U: Cyberdrugs: a cross-sectional study of online pharmacies characteristics. Eur J Public Health 2009, 19:375-7.

11. Wilkinson $\mathrm{E}:$ Is the online drugs market putting patients at risk? Nurs Times 2006, 102:23-4.

12. Levaggi R, Orizio G, Domenighini S, Bressanelli M, Schulz PJ, Zani C, Caimi $\mathrm{L}$, Gelatti U: Marketing and pricing strategies of online pharmacies. Health Policy 2009, 92:187-96.

13. Berkowitz EN: The evolution of public relations and the use of the internet: the implications for health care organizations. Health Mark $Q$ 2007, 24:117-30
14. Andreassen HK, Bujnowska-Fedak MM, Chronaki CE, Dumitru RC, Pudule I, Santana S, Voss H, Wynn R: European citizens' use of E-health services: a study of seven countries. BMC Public Health 2007, 7:53.

15. Mira JJ, Llinás G, Tomás O, Pérez-Jover V: Quality of websites in Spanish public hospitals. Med Inform Internet Med 2006, 31:23-44

16. Norem J, Moen MA: The Websites of Norwegian hospitals: do they meet national guidelines and patient's expectations? J Telemed Telecare 2004, 10:272-6.

17. Eysenbach G: Medicine 2.0: Social Networking, Collaboration, Participation, Apomediation, and Openness. J Med Internet Res 2008, 10(3):e22

18. Giustini D: How Web 2.0 is changing medicine. BMJ 2006, 333:1283-4.

19. Jommi $C$, Cantù $E$, Anessi-Pessina E: New funding arrangements in the Italian National Health Service. Int J Health Plann Manage 2001, 16:347-68.

20. Riffe D, Lacy S, Fico FG: Analyzing media messages. Using quantitative content analysis in research Mahwah, New Jersey: Lawrence Erlbaum; 2005.

21. Eysenbach G, Powell J, Kuss O, Sa ER: Empirical studies assessing the quality of health information for consumers on the world wide web: a systematic review. JAMA 2002, 287:2691-700.

22. Minerva working group 5: Quality Principles for Cultural Websites: a handbook. 2005. [http://www.minervaeurope.org/publications/ qualitycommentary/qualitycommentary050314final.pdf.

23. Web Accessibility Initiative (WAI): World Wide WebConsortium (W3C). [http://www.w3.org/WAI//

24. Cascading Style Sheets Home Page: World Wide WebConsortium (W3C). [http://www.w3.org/Style/CSS/]

25. XHTML2 Working Group Home Page: World Wide WebConsortium (W3C). [http://www.w3.org/MarkUp/.

26. HON code section for medical professionals. Health On the Net Foundation Non Governmental Organization [http://www.hon.ch/ HONcode/Pro/intro.html]

27. Llinás G, Rodríguez-Iñesta D, Mira JJ, Lorenzo S, Aibar C: A comparison of websites from Spanish, American and British hospitals. Methods InfMed 2008, 47:124-30

28. Kind T, Wheeler KL, Robinson B, Cabana MD: Do the Leading Children's Hospitals have Quality Web Sites? A Description of Children's Hospital Web Sites. J Med Internet Res 2004, 6(2):e20.

29. National Health Service (NHS): Hospital choice. [http://www.nhs.uk/ choiceinthenhs/yourchoices/hospitalchoice/pages/ choosingahospital.aspx]

30. Ministère de la Santé et des Sports. Plateforme d'informations sur les établissements de santé: PLATINES RESULTATS 2007 [http:// www.platines.sante.gouv.fr/]. In French. French Ministry of Health and Sports. Information platform on health institutions: PLATINES results 2007

31. Freeman B, Chapman S: Gone viral? Heard the buzz? A guide for public health practitioners and researchers on how Web 2.0 can subvert advertising restrictions and spread health information. J Epidemiol Community Health 2008, 62:778-82.

Pre-publication history

The pre-publication history for this paper can be accessed here: http://www.biomedcentral.com/1472-6947/10/17/prepub

doi: 10.1186/1472-6947-10-17

Cite this article as: Maifredi et al., Italian hospitals on the web: a cross-sectional analysis of official websites BMC Medical Informatics and Decision Mak ing 2010, 10:17 